\title{
La escucha en la ciudad contemporánea. Aproximaciones teóricas ${ }^{1}$ The listening in the contemporary city. Theoretical approaches
}

\author{
Gustavo Alfonso Galván Cázares² \\ http://orcid.org/0000-0002-5674-4274 \\ José Guadalupe Rivera González \\ http://orcid.org/0000-0002-2108-3963
}

Primera versión recibida: 17 de febrero de 2021

Última versión recibida: 25 de junio de 2021

\section{Resumen}

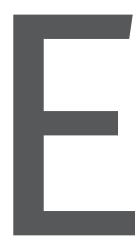

n el presente artículo se plantean diferentes aproximaciones teóricas en torno al sonido y al acto de escuchar en la ciudad contemporánea, así como los procesos de producción y significación de la ciudad a través de dicho acto. El objetivo central de este escrito es sumar a las discusiones interdisciplinares del binomio sonido/escucha en el ámbito de los estudios urbanos, ya que dichas disertaciones aún son escasas en el contexto latinoamericano. Para ello, en primera instancia se argumenta la escucha como un medio epistémico por el cual se aprende sobre la ciudad. Posteriormente, se analizan algunas implicaciones de diferentes procesos globales en las prácticas aurales de los urbanitas. Por último, se expone la necesidad de apelar a la escucha ciudadana como un elemento esencial para tomar en cuenta en la planeación, construcción, remodelación y planes de reordenamiento territorial, así como en toda transformación física y simbólica de la ciudad. En este contexto, se analizan algunas premisas teóricas sobre la experimentación del espacio público a través de escucharlo,

1 Este artículo se desprende del entramado teórico de la tesis doctoral del primer autor en la que se analizan las implicaciones de los procesos patrimoniales en las prácticas de escucha de habitantes y usuarios de centros históricos latinoamericanos.

2 Universidad Autónoma de San Luis Potosí (UASLP). Estudiante de doctorado del Programa de Estudios Latinoamericanos en Territorio, Sociedad y Cultura.

3 Universidad Autónoma de San Luis Potosí (UASLP). Facultad de Ciencias Sociales y Humanidades-Profesor-investigador de tiempo completo. Miembro del Sistema Nacional de Investigadores Nivel I. Coordinador de la Licenciatura en Antropología-UASLP.

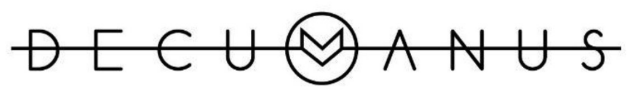

REVISTA INTERDISCIPLINARIA SOBRE ESTUDIOS URBANOS 
reconociendo al sonido como un componente que permite una apropiación y significación del espacio, así como un elemento de cohesión social y generador de identidades.

Palabras clave: escucha; sonido; ciudad; espacio público.

\section{Abstract}

The present article sets out different theoretical approaches around the sound and the act of listening in the contemporary city as well as the processes of production and significance of the city through the mentioned act. The central goal of this writing is to contribute to the interdisciplinary discussions about the coupling of sound/ listening in the field of urban studies since the aforementioned dissertations are still scarce in the Latin American context. To this effect, firstly, listening as an epistemic means by which the city is learned is discussed. Afterwards, some implications about different global processes in the urbanites' aural practices are analyzed. Lastly, the necessity of appealing to citizen's listening as an essential element to consider throughout the planning, construction, remodeling and the plans of territorial restructuring as well as in every physical and symbolic transformation of the city is presented. In this context some theoretical premises about the experimentation of the public space through hearing, being aware of the sound as a component that allows an appropriation and significance of the space as well as an element of social cohesion and generator of identities are analyzed.

Keywords: listening; sound; city; public space.

\section{Consideraciones epistemológicas y conceptuales sobre la escucha en la ciudad}

Durante las últimas décadas, la corriente multidisciplinaria de los estudios sonoros ha venido en aumento, lo que ha permitido consolidar diversas escuelas y centros especializados que tienen como punto de anclaje el sonido y la escucha, para analizar una gran variedad de fenómenos sociales, culturales y de diseño. Es importante mencionar que, aunque las investigaciones realizadas acerca del sonido y la escucha muestran una gran diversidad de temáticas, las relacionadas con los estudios en contextos urbanos son las más comunes. No obstante, Latinoamérica muestra cierto rezago en este tópico, pues si bien los estudios urbanos latinoamericanos han realizado importantes aportes a diferentes temas de vanguardia, los relacionados con las prácticas sonoras y de escucha en las ciudades son poco abordados. Es por ello que en este artículo se plantea un conjunto de disertaciones teóricas, que ponen de manifiesto la importancia de impulsar la investigación y el trabajo multidisciplinar en torno a estas materias. Para ello, se apela a diversas discusiones de los estudios sonoros y de la auralidad.

Los antecedentes sobre las discusiones teóricas de la escucha, se remontan a la idea de soundscape (paisaje sonoro), propuesta por Murray Schafer (1977), quien postuló este concepto como el ambiente sonoro total que existe en un determinado lugar. Schafer también fue pionero de la ecología acústica, disciplina hoy reconocida a nivel mundial; sin embargo, fue el antropólogo y etnomusicólogo Steven Feld (2015), quien llevó la escu-

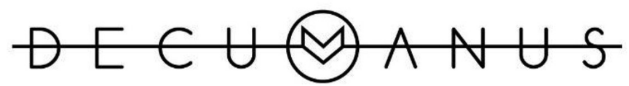

REVISTA INTERDISCIPLINARIA SOBRE ESTUDIOS URBANOS 
cha a los campos de las disertaciones epistemológicas acuñando el término acustemología.

La acustemología sitúa a la escucha como medio de generación de conocimiento, anteponiendo el acto de escuchar al mismo evento sonoro; a su vez, se advierte que existen diferentes formas de escuchar, las cuales están determinadas por el contexto cultural. En palabras de Feld (2015), la acustemología es una forma de interpretar y aprender el mundo a través de escucharlo. Aquí vale la pena distinguir entre oír y escuchar, entendiendo lo primero como el acto físico de la audición, por el cual se tiene un primer acercamiento auditivo al entorno; mientras que por lo segundo, se debe apelar al acto de otorgar significado a lo que se oye, en lo cual intervienen procesos cognitivos relacionados con las epistemes socioculturales.

La escucha es un fenómeno de estudio complejo, pues los sonidos tienen valores significativos diferentes en cada contexto, los cuales pueden ser resignificados a través del tiempo. La escucha como fenómeno situado, mediado y encarnado (Domínguez, 2019) conlleva a una serie de aspectos que condicionan la forma de escuchar, tales como los biográficos, tecnológicos, estéticos y simbólicos. En este tenor, el acto de escuchar como práctica sociocultural está vinculada a diferentes procesos que obedecen a intereses económicos o políticos y a otras asociaciones de poder (Bieletto, 2019).

Por lo tanto, se puede ir esbozando la escucha como práctica cultural y social, ya que los individuos comparten y significan el ambiente sonoro que se gesta en torno a ellos. Algo importante de mencionar es que el sonido adquiere relevancia de cohesión social y de reconocimiento, ya que todas las personas contribuyen en mayor o menor medida a la generación del ambiente sonoro que escuchan; a su vez, los integrantes de una misma colectividad se reconocen a través de sus dinámicas aurales, debido a los condicionamientos de los cuales se habló arriba. Ahora bien, no se puede concebir la escucha como un fenómeno en el cual solo se apele a dinámicas colectivas, pues el acto de escuchar también está mediado por procesos subjetivos, por lo que la escucha de cada individuo presenta variaciones; las cuales también pueden estar condicionadas por cada situación particular.

En este tenor, se pueden argumentar dos premisas: la primera es que, aunque existen sujeciones socioculturales, todo ser humano escucha de manera diferente a partir de su subjetividad. La segunda es que no todo lo que suena en un tiempo/espacio determinado es escuchado por todos quienes conviven en este, pues como menciona Pelinski (2007), "La vida cotidiana tiene una banda sonora. Si no la escuchamos, es porque ya estamos acostumbrados a oírla"; esto, a su vez, apela a los procesos de adaptación sonora (Domínguez, 2014), pero también refiere a la significación que tienen algunos sonidos para ciertas personas, mientras que para otras estos mismos sonidos pasan inadvertidos.

Por consiguiente, la escucha como experiencia colectiva y subjetiva es un elemento por el cual el individuo y los grupos construyen y reconstruyen su memoria e identidad (Polti, 2018), pero también es una apertura al reconocimiento de la alteridad (García, 2019). En este sentido, la escucha se puede sintetizar como una práctica corpórea y ontológica detonada por el sonido, que permite obtener y mediar los conocimientos para realizar otras prácticas, como la comunicación, la socialización, la experimentación del lugar, entre otras muchas.

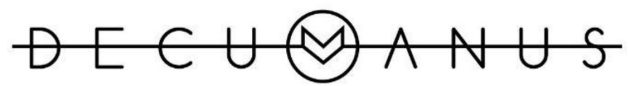

REVISTA INTERDISCIPLINARIA SOBRE ESTUDIOS URBANOS
Núm. 7. Vol. 7. Mayo 2021-Octubre 2021. Instituto de Arquitectura, Diseño y Arte. Universidad Autónoma de Ciudad Juárez. ISSN: 2448-900X 
Al hacer referencia a la escucha como un elemento epistémico es imposible no pensar en las discusiones sobre la hegemonía de la vista en relación con los demás sentidos, en especial en la era moderna donde se considera ha predominado una epistemología de lo visual, encontrando una posible explicación con el invento de la imprenta que permite entender el cambio de paradigma en la transmisión del conocimiento, que pasó de ser oral a ser escrito. Sin embargo, la escucha como un medio productor de conocimiento ha jugado un papel igual de importante que la vista en la construcción de las sociedades modernas (Erlmann, 2010). Dentro de esta misma narrativa, Erlmann puntualiza que los estudios sonoros y de la auralidad no buscan una sustitución o empoderamiento de la escucha sobre la vista o los demás sentidos, sino una comprensión de los alcances epistemológicos del acto de escuchar.

En este contexto, es importante mencionar la propuesta de Roberto Barbanti (2017), quien bajo las premisas del concepto de acustemología del ya referido Steven Feld, propone el término acusia como el conocimiento que surge a partir de escuchar. La acustemología y la acusia persiguen casi los mismos fines, pero la justificación de Barbanti para usar un nuevo término está sustentada en la raíz etimológica de los conceptos, pues señala que todo el conocimiento occidental está sustentado en la palabra teoría, que está relacionada con la forma de saber a partir del hecho de mirar, por lo que propone la acusia -del griego akousis (oído)- como la forma de teorizar a partir de escuchar.

Para significar esta superación del concepto de teoría, propongo forjar otro término, que (inscribiéndose igualmente en los orígenes de la etimología griega) sea tan "hablante" como aquel, pero con la capacidad de hacernos entender el mundo al referir, justamente, al oído (Barbanti, 2017, p. 101).

Una de las principales diferencias entre los conceptos de acustemología y acusia son los contextos de donde emergen. La acustemología propuesta por Feld surge en el estudio de la música y la cotidianidad sonora de los Kaluli, un grupo étnico de Papúa Nueva Guinea. Por otra parte, el concepto de acusia germina bajo la premisa de reteorizar la ciudad a partir de la escucha. Otra diferencia es la postura desde donde está sustentado cada concepto: por el lado de Feld parte de la antropología del sonido, mientras que Barbanti encuentra su anclaje desde una perspectiva ecosófica.

Entre otras premisas, tanto de la acustemología como de la acusia, se pueden destacar las inquietudes por romper el paradigma del antropocentrismo sonoro; en otras palabras, no solamente analizar los sonidos producidos por las actividades humanas (antropofonías), sino también estudiar las epistemes producidas al escuchar los sonidos por alguna especie animal (biofonías) y los sonidos producidos por fenómenos naturales (geofonías). Para los intereses de este escrito, se puede enunciar la existencia de un interés en la escucha como una forma de aprender, experimentar y, en general, un modo de vivir la ciudad desde la experiencia de lo sonoro.

Para ejemplificar lo anterior, se hace referencia a la instalación sonora que montó el artista Pablo Delgado, en el London MexFest (Secretaría de Cultura, 2013). En esa ocasión el mencionado artista refirió que cada ciudad tiene una identidad sonora; en este tenor su instalación representaba la metáfora de lo ajeno, ya que es posible escuchar sonidos

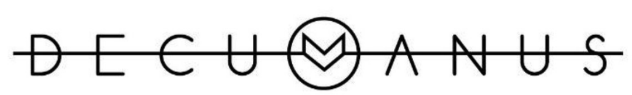

REVISTA INTERDISCIPLINARIA SOBRE ESTUDIOS URBANOS 
típicos de la Ciudad de México, como organilleros, el sonido del afilador, el vendedor de tamales, entre otros, y como sonido de fondo, el sonido de lluvia con truenos grabado en la Ciudad de México. Cuando le preguntaron el porqué de la lluvia con truenos, el artista contestó lo siguiente:

Porque la lluvia es un sonido que caracteriza a Londres. La lluvia con truenos de México suena artificial frente a la lluvia de Londres, acá es ligera, no hay condensación, no hay truenos, en el Distrito Federal se escuchan las gotas caer. Quiero mostrar cosas que en México se nos hacen ya comunes al oído, pero que aqui van a adoptar un carácter un poco extraño, ya que no se sabe que son, no se identifica el contexto, es como tratar de crear un ambiente surrealista donde todo está anclado al sonido (Delgado, 2013). ${ }^{4}$

Puntualizando en el ejemplo de la lluvia que es un sonido que caracteriza a la ciudad de Londres, y tomando en cuenta que el tipo de lluvia de esta ciudad es muy particular, es muy probable que una persona que haya vivido durante un determinado tiempo en Londres, si le dieran a escuchar varios audios con lluvia de diferentes lugares pudiera reconocer fácilmente el sonido de la lluvia de esta ciudad. Este reconocimiento del lugar, a partir de la escucha y la asociación de sonidos a la representación del lugar, son parte de los alcances de generación del conocimiento de la acustemología y la acusia, lo cual se puede resumir en los siguientes puntos en donde se toma la acustemología como forma general de adquirir conocimiento, a través de la escucha, y la acusia como forma particular de aprender la ciudad, a partir de la escucha.

De lo señalado hasta el momento, se puede destacar lo siguiente: 1. La acustemología da pie a entender y acceder a los códigos sonoros que emiten los eventos a los que no se tiene acceso con la vista, por ejemplo, las alarmas. 2. Cuando la vista en un espacio determinado es limitada o restringida, la acustemología permite entender las dinámicas de cualquier lugar con el simple acto de escuchar. ${ }^{5}$ 3. La acustemología permite mediar las formas de comunicación y comportamiento en un espacio determinado. ${ }^{6} 4$. La acustemología está íntimamente relacionada con agentes que conforman la cultura; lo anterior se puede entender a partir de la producción de la sonoridad derivado de un conjunto de tradiciones, fiestas, creencias, vocabulario, cosmovisiones, entre otras formas en que se relaciona el ser humano con su entorno.

En cuanto a la acusia se enuncia que: 1 . La acusia permite acceder a nuevas formas de reinterpretar la concepción de ciudad, a partir de la escucha. 2. La acusia remite a nuevas formas de estudiar los procesos de subjetivación en la ciudad. 3. La acusia da pie a

4 Consultado en: https://www.gob.mx/cultura/prensa/la-identidad-sonora-de-mexico-presente-en-el-london-mexfest-pablo-delgado

5 Un ejemplo de esto es posible apreciarlo en el texto de Tom Rice (2003) "Soundselves: An Acoustemology of Sound and Self in the Edinburgh Royal Infirmary". En este se describe cómo los pacientes de un hospital cuya visión estaba limitada por las cortinas que rodeaban sus camas, aprendieron las dinámicas del hospital a través de la escucha.

6 Parte de esta discusión es posible encontrarla en la publicación "Alarmas y sirenas: sonotopías de la conmoción cotidiana" del autor Noel García López (2005), quien argumenta: "No es que un espacio se llene, se observe, se huela, se palpe o se oiga, sino que un espacio implica/compone una forma de palpar, de ver y oír, de pensar o desplazarse" (p. 14).

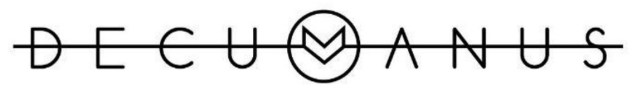

REVISTA INTERDISCIPLINARIA SOBRE ESTUDIOS URBANOS
Núm. 7. Vol. 7. Mayo 2021-Octubre 2021. Instituto de Arquitectura, Diseño y Arte. Universidad Autónoma de Ciudad Juárez. ISSN: 2448-900X 
preponderar las biofonías y geofonías al mismo nivel que las antropofonías dominantes en el ambiente sonoro de la ciudad. 4. La acusia posibilita analizar las dinámicas de la cotidianidad de la ciudad, a través del acto de escuchar.

Por lo tanto, se pueden concebir ambos conceptos como complementarios, ya que persiguen un mismo fin: analizar y evidenciar el conocimiento que se produce mediante las prácticas de la escucha. Ambas ideas son relevantes para este artículo, pues la premisa central de este refiere que la escucha determina formas particulares de aprender, experimentar y significar la ciudad.

\section{Sonido y escucha en la ciudad contemporánea}

En este apartado se busca una aproximación teórica de las complejidades que se derivan del análisis del binomio sonido/escucha en la ciudad, partiendo de los conocimientos dados sobre los procesos de capitalismo y globalización de la ciudad contemporánea, que la legitiman como vanguardista, entendiendo el término de vanguardia como los procesos urbanísticos, tecnológicos, industriales, comerciales, y de los diferentes tipos de consumo. Se realizan análisis breves sobre ciertas dinámicas sonoras relacionadas con las transformaciones de la ciudad, las conductas a las que induce el sonido, así como con la emisión de sonidos de altos decibeles, todo ello relacionado con las implicaciones reflejadas en las prácticas de la escucha y en aspectos como la habitabilidad. Uno de los primeros estudiosos de la ciudad fue el sociólogo alemán Georg Simmel (2016), quien desde principios del siglo xx puntualizó algunos aspectos de la ciudad que hasta el día de hoy siguen vigentes como es posible leer a continuación:

Las grandes ciudades han sido desde siempre el asiento de la economía monetaria, ya que la variedad y la concentración de los intercambios económicos dan una importancia al medio de cambio a la que no se habría llegado con la escasez de trueques del comercio rural (p. 61).

En los estudios de la ciudad de Simmel, ya eran notorias algunas inquietudes que se discutirían a profundidad durante gran parte del siglo xx, por distintos autores. Tal es el caso de algunos miembros de la Escuela de Frankfurt, como Walter Benjamin, Theodor Adorno y Max Horkheimer, estos últimos entramando la problemática acerca de la cultura de masas y el consumo en la ciudad moderna. Las premisas de Simmel (2016), a las que hago referencia, son: la producción y el consumo como eje cotidiano de la ciudad; el individualismo exacerbado como agente que impulsa la vida económica; la ciudad como un espacio centralizado $y$, por último, la ciudad como un lugar donde sucede una gran cantidad de acontecimientos al mismo tiempo, sin aparente relación, pero con total codependencia.

Carmen Pardo (2017) estudia la ciudad contemporánea desde el ámbito sonoro, deduciendo que el consumo capitalista y las dinámicas que de allí emanan tienden a cambiar de manera contundente la sonoridad de las ciudades, mencionando que la gran cantidad de actividades económicas que se multiplican de manera acelerada en la ciudad derivan en la aparición continua de nuevos sonidos y la paulatina desaparición de otros. Ahora

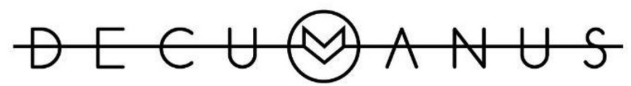

REVISTA INTERDISCIPLINARIA SOBRE ESTUDIOS URBANOS 
bien, es importante señalar que el surgimiento de sonidos y la desaparición de algunos es algo inevitable, pues la mayor parte de los sonidos de la ciudad provienen de las actividades humanas que alli se realizan. Por lo que, entendiendo la cualidad de inmediatez de cambios de la época contemporánea, muchas actividades desaparecen, mientras que otras se incorporan diariamente a las ciudades. Al respecto, la misma autora refiere:

En correspondencia con el sistema económico neoliberal que traza el desarrollo de toda ciudad, la noción de ciudad-máquina cuenta con un amplio recorrido conceptual que ha llevado también a calificar la ciudad como una "máquina de crecimiento"; como una "máquina de diversión" o, incluso, como una "máquina de movilidad", entre otros apelativos (Pardo, 2017, p. 115).

Esta idea de la ciudad-máquina resulta ser un buen incentivo para reflexionar sobre la diversidad sonora que es posible encontrar en la ciudad, a través de una escucha atenta, ya que revela una gran cantidad de conflictos sonoros, pues muchas actividades ocurren al mismo tiempo y algunas con sonidos más fuertes que otras; efectos como el enmascaramiento sonoro y la hipersonorización ${ }^{8}$ están a la orden del día en la ciudad. Al respecto, Carmen Pardo (2017) señala que la sonoridad de la ciudad se presenta como un proceso en donde coexisten una multiplicidad de formas de escuchar; además, al recorrer la ciudad las personas se enfrentan a una infinidad de formas acústicas de las que en su mayoría sus mismos habitantes son corresponsables.

Si bien algunos autores como Carles y Palmese (2004) sostienen que cada ciudad tiene sonidos representativos que propician en los ciudadanos maneras únicas de vivir la ciudad, Carmen Pardo (2017) predice una eventual uniformización sonora derivada de los procesos capitalistas, pues fenómenos como la globalización paulatinamente han introducido actividades económicas y de consumo semejantes en la mayoría de las ciudades del mundo, argumentando lo siguiente:

Ciertamente, todas las grandes ciudades tienden a reproducir las mismas imágenes publicitarias, los mismos centros comerciales; últimamente también, los mismos museos; y tienden a generar el mismo tipo de sonidos. $Y$ en este proceso, las variantes se van reduciendo rápidamente. En esta progresiva uniformización, los ciudadanos tal vez no reconocen su ciudad como propia, pero son capaces de trazar los rasgos preponderantes de toda ciudad contemporánea (p. 116).

Estos argumentos de Pardo acerca de la reproducción y el consumo estandarizado de la ciudad contemporánea están ligados a la idea de la sociedad del hiperconsumo (Lipovetsky, 2014), ya que el urbanita aspira a tener en su ciudad las grandes marcas, las franquicias de moda y todas las actividades de consumo que legitimen su ciudad como

7 El efecto del enmascaramiento sonoro sucede cuando sonidos de altos decibeles, se sobreponen auditivamente a sonoridades más débiles, privando a estas de ser escuchadas.

8 La hipersonorización es el exceso de sonido. Lo que Murray Schafer (1977) definiera como paisaje sonoro lo-fi, es decir, paisajes sonoros saturados que provocan una baja fidelidad auditiva y, en ocasiones, dañinos para la salud.

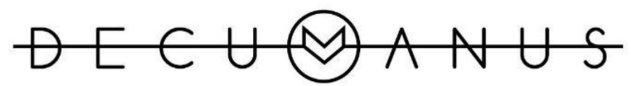

REVISTA INTERDISCIPLINARIA SOBRE ESTUDIOS URBANOS
Núm. 7. Vol. 7. Mayo 2021-Octubre 2021. Instituto de Arquitectura, Diseño y Arte. Universidad Autónoma de Ciudad Juárez. ISSN: 2448-900X 
vanguardista. Estos aspectos de la globalización repercuten en la reproducción de la ciudad a manera de molde, lo que incide en que la sonoridad del espacio público sea cada vez más parecida entre distintas ciudades imponiendo una paulatina estandarización de la escucha (De Gortari, 2013).

Por lo tanto, se debe tomar conciencia de que todo cambio de infraestructura o físico de la ciudad deriva en mayor o menor medida en un cambio en su sonoridad y, por consiguiente, en las prácticas de escucha de sus ciudadanos. Ante esto, es importante considerar la variable sonora al momento del diseño urbano y arquitectónico (López, 2001); de igual manera, dicha variable debería influir en la selección de los materiales de construcción, así como en ornamentos que funcionen a manera de pantalla o paneles acústicos. ${ }^{9}$

Al igual que las transformaciones físicas, también los cambios e incorporaciones de nuevas actividades en la ciudad conllevan cambios sustanciales en la escucha. Por lo que es importante apelar al sentir y pensar ciudadano, previo a cualquier cambio que se genere en la ciudad; en este caso teniendo como consideración especial la escucha, pero de igual manera se deben tomar en cuenta los demás canales sensoriales. Un ejemplo de la mala planeación, tanto física, sensorial y, por consiguiente, sonora de la ciudad, lo expone Domínguez (2014) en su publicación "Vivir con ruido en la Ciudad de México. El proceso de adaptación a los entornos acústicamente hostiles".

En esta Domínguez advierte sobre los problemas fisiológicos que puede causar la exposición continua a sonidos de altos decibeles, así como el análisis cualitativo de la calidad de vida y los procesos de habituación de personas que viven o trabajan cerca de lugares donde se generan sonoridades estruendosas. El caso de estudio de este texto es el trabajo etnográfico realizado con personas que viven cerca del Aeropuerto Internacional de la Ciudad de México en donde se expone la ambivalencia de individuos que se han adecuado a este ambiente sonoro y otros que, a pesar de su realidad de escucha cotidiana, no lo han hecho. Esta investigación pone en relevancia aspectos como el derecho a la ciudad, las formas de cohabitación, las características holísticas a las que se debería apelar en la planeación de las ciudades y las necesidades de un reordenamiento territorial en el cual se focalicen aspectos integrales que influyan en la manera de vivir la ciudad; sin duda, uno de ellos es el sonoro.

Otro aspecto para tomar en cuenta en la escucha de la ciudad contemporánea es el relacionado con los cambios tecnológicos que han inundado las urbes, sobre todo en las últimas dos décadas. Hoy en día es común escuchar altoparlantes en cualquier parte de la ciudad, sobre todo en espacios urbanos relacionados con el comercio. También el sonido de las alarmas y sirenas de todo tipo son parte ya de las urbes; además, estos sonidos repercuten en las dinámicas cotidianas y crean comportamientos específicos (García, 2005). Por ejemplo, al escuchar la alarma sísmica de la Ciudad de México, la alarma contra incendios del metro o el simple hecho de escuchar la sirena de los servicios de emergencias provoca un comportamiento de solidaridad de los conductores al ceder el paso a los vehículos de urgencias. En otros contextos, las alarmas de los coches, de los negocios o de las viviendas propician una escucha alerta en la ciudad, pues estas comunican actos de peligro o eventualidad que se deben atender a la inmediatez.

9 Este tipo de especificaciones de acústica urbana pueden ser consultadas en el libro Guía sonora para una ciudad, de Jimena de Gortari (2013).

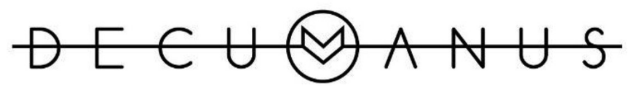

REVISTA INTERDISCIPLINARIA SOBRE ESTUDIOS URBANOS
Núm. 7. Vol. 7. Mayo 2021-Octubre 2021. Instituto de Arquitectura, Diseño y Arte. Universidad Autónoma de Ciudad Juárez. ISSN: 2448-900X 
La impronta sonora de la tecnología en la ciudad a menudo es bien recibida por los urbanitas; no obstante, en ciertos entornos los sonidos relacionados con la tecnología resultan hostiles, tal es el caso de las personas que habitan cerca de antros, bares y demás establecimientos nocturnos que emiten altos decibeles a través de altoparlantes, lo que deriva en que estos sonidos tecnológicos sean concebidos como contaminación acústica y condicionantes de una mala calidad habitacional. A pesar de ello, estas dinámicas son cada vez más comunes en distintos puntos de las ciudades que se adaptan para el ocio dentro o muy cerca de zonas habitacionales.

Resulta relevante indicar que, si bien dentro de las políticas públicas y reglamentos de ordenamiento territorial y ecología, se establecen claros lineamientos sobre la ubicación territorial de este tipo de establecimientos, así como las limitantes de decibeles permitidos, estos reglamentos parecen no ponerse en práctica, por lo menos en el contexto latinoamericano. Un claro ejemplo son los centros de las ciudades, los cuales tienden a tener procesos de patrimonialización, turistificación y una paulatina gentrificación de distintos tipos, tal como lo dejan notar los textos de Hiernaux y González (2014), Delgadillo (2015), Deávila (2015), Gasca (2016), Roldán (2017), Argüello (2018), entre otras muchas publicaciones respecto a estos temas.

Es oportuno mencionar que no se pretende idealizar el silencio o una ciudad sin ruido como un lugar perfecto para habitar, tampoco es la intención postular el ruido como el problema central de la ciudad contemporánea, tan es así que, apenas en este párrafo, se ha argumentado la conceptualización de ruido, prefiriendo a lo largo del texto buscar símiles, como altos decibeles, hipersonorización y sonidos estruendosos, debido a que la postulación del concepto de ruido siempre conlleva a connotaciones negativas en las cuales el sonido considerado como ruido pareciera no tener valor alguno; además, el ruido también está ligado a una interpretación subjetiva, pues, aunque hay sonidos planos, como los de motores y máquinas, que pueden ser denominados ruido, existen un sinfín de sonidos cotidianos que subjetivamente podrían tener esta categorización.

El punto central y sin extender más este asunto es que el ruido no debe ser considerado únicamente como sonidos de altos decibeles, pues muchos de estos sonidos estruendosos son parte de la identidad y las costumbres de ciertas poblaciones. Un ejemplo de ello es el sonido de los fuegos artificiales de las fiestas patronales, que aún hoy son muy comunes en ciertas ciudades de México. En síntesis, un sonido que produce un grupo o individuo puede ser concebido como deseado cuando él lo produce o puede volverse molesto o indeseado cuando otro grupo o persona lo genera (Paparrigopoulos, 2017).

Este tipo de circunstancias pone de manifiesto que el estudio de la escucha en la ciudad es bastante complejo; sin embargo, dicho análisis es necesario, ya que permite un análisis de la sociedad y de la cultura desde otra perspectiva al clásico régimen ocularcentrista, o como lo apuntaba Barbanti (2017), da pie a reteorizar la ciudad a partir de la escucha. De igual modo, es apremiante que todas las disciplinas afines al estudio y la producción del hábitat humano tomen en cuenta la variable sonora, así como ampliar la participación de diferentes expertos en los grupos que participan en la planificación y expansión de las ciudades. A su vez, es fundamental tomar en cuenta el sentir y pensar de la ciudadanía en toda transformación física y simbólica de la urbe, y no solo imponer

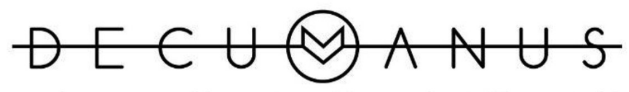

REVISTA INTERDISCIPLINARIA SOBRE ESTUDIOS URBANOS
Núm. 7. Vol. 7. Mayo 2021-Octubre 2021. Instituto de Arquitectura, Diseño y Arte. Universidad Autónoma de Ciudad Juárez. ISSN: 2448-900X 
cambios en pro de procesos económicos y de modernización. En otras palabras, planificar, construir y reordenar una ciudad integral y democrática.

\section{La experimentación del espacio público a través de la escucha}

En este último apartado, se recupera la premisa central de la acustemología y la acusia, la cual refiere a la escucha como medio de generación de conocimiento y comprensión del mundo circundante. Bajo esta idea es de interés argumentar la importancia del estudio de la escucha en la ciudad contemporánea como un recurso útil que permita un mejor entendimiento de asuntos como la habitabilidad, la identidad socio-territorial, los imaginarios urbanos y la experimentación del espacio público. Se desarrolla este último tópico para ejemplificar la argumentación, analizando la reciprocidad de la producción escucha/ espacio público, a partir del constructo de experimentar y significar el lugar.

Las formas de experimentar el espacio público, a partir de la escucha, conllevan en primera instancia a reconocer dicho espacio como un lugar sonoro per se. En este sentido, el sonido determina un conjunto de saberes, prácticas y sensibilidades que son parte de la vida cotidiana y que se construyen a través del acto de escuchar (Polti, 2011). Un factor importante que es relevante tomar en cuenta es la cualidad ubicua del sonido, que refiere que el sonido no solo existe en el lugar donde se reproduce, sino hasta el último rincón donde se escucha (Augoyard, 1997). Lo que implica clasificar el sonido como un elemento intrusivo, ya que sus delimitaciones son completamente diferentes a los límites y fronteras visibles (Celedón, 2015).

En la ciudad se percibe el campo acústico desde el interior, pues en cualquier punto en que se encuentre un individuo el sonido le llegará por todas partes (Berenguer, 2017). En consecuencia, se puede deducir que el sonido es un elemento del cual no se puede huir o evitar en el espacio público, pues no se tienen párpados en los oídos (Domínguez, 2011). A no ser que el transeúnte decida encerrarse dentro de su propia burbuja sonora, como ocurre al escuchar música con audífonos mientras se transita por la vía pública, como lo analizan Thibaud (2003) y Bull (2004).

Uno de los fenómenos más relevantes para examinar la experimentación del espacio público, a través de escucharlo, es el sonido del tráfico, pues si bien en los últimos años las empresas automotrices han puesto atención al aspecto sonoro que producen los motores de los automóviles, los cuales cada vez son más silenciosos, el crecimiento demográfico y las aspiraciones consumistas que promueven la obtención de un vehículo como parte esencial de las necesidades en la ciudad, ha derivado en la adquisición masiva de automóviles. En este tenor, a diferencia de otras partes del mundo donde los vehículos de modelos pasados se desechan, es común que en ciudades latinoamericanas aún se sigan usando una gran cantidad de coches que tienen más de veinte años de antigüedad. Todo este tipo de cuestiones ha derivado en que el tráfico vehicular aumente a niveles preocupantes en las ciudades latinoamericanas causando problemas, tanto de mala calidad del aire como de contaminación acústica.

Otro factor importante acerca de la experimentación del espacio público, a través de la escucha, es la territorialización. Aquí se desea hacer la acotación de que el sonido es un elemento tanto comunicativo como territorializante en casi todo el reino animal, pero

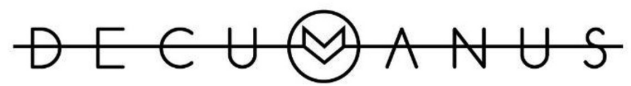

REVISTA INTERDISCIPLINARIA SOBRE ESTUDIOS URBANOS 
a diferencia de los seres humanos los animales han evolucionado sus emisiones sonoras al ocupar un nicho acústico específico al emitir vibraciones en ciertas frecuencias, lo que anula el enmascaramiento sonoro y permite un equilibrio acústico en los ecosistemas naturales (Krause, 1993).

La territorialidad sonora de un espacio urbano es muy diferente a la de un ecosistema natural, pues el ser humano no tiene la capacidad de anular ciertos sonidos y solo escuchar los que le interesan; simple y sencillamente escucha los sonidos más fuertes, quedando completamente enmascarados los débiles, a menos que sus características tímbricas y físicas permitan a estos últimos ser escuchados en medio de la masa sonora urbana. Pero lo que aquí interesa es la interrogante: ¿por qué el ser humano emite sonidos fuertes de manera intencional? Al respecto, Domínguez (2017) señala:

Alzar la voz es una práctica de apropiación espacial, quien alza la voz domina sonoramente un espacio, y en su entorno se proyecta un campo acústico y se delimita un territorio, tan amplio o reducido según sea la fuerza de la emisión (p. 49).

En consecuencia, emitir sonidos fuertes de manera intencional tiene que ver directamente con un acto comunicativo, pero también territorial. Por ejemplo, las personas que ponen música a todo volumen en sus viviendas, de manera consciente o inconsciente, es una forma de territorializar; lo mismo sucede con los altavoces de los comercios, que buscan llamar la atención de sus clientes mediante el perifoneo y la música de sus altoparlantes que territorializan el espacio. Es importante aclarar que aquí se refiere a territorializar como una forma de apropiación espacial mediante el sonido, que si bien físicamente puede ser cuantificable al medir hasta dónde se escucha un sonido, la variable referida es la apropiación sonora simbólica del territorio, apelando a una de las premisas de Sack (1983), quien refiere que una de las características de la territorialidad es la influencia que un individuo o una colectividad tiene sobre el territorio de otra persona o colectividad. En este caso, la cualidad ubicua del sonido lo convierte en un elemento de territorialidad por su misma naturaleza.

Por otra parte, la escucha permite, entre otras cosas, la orientación y el reconocimiento del espacio público, a través de sus sonidos; sin embargo, como se ha argumentado a lo largo de este documento, las ciudades tienden a una uniformización de sus dinámicas urbanas, comerciales y socioculturales. Lo que repercute en la transformación, enmascaramiento o desaparición de algunos sonidos por los cuales los ciudadanos identifican determinados lugares o espacios públicos, por lo que para finalizar este apartado queremos hacer referencia a lo que en los estudios sonoros se ha argumentado como identidad sonora.

La identidad sonora es un tema que se ha estudiado a profundidad en distintas investigaciones que analizan la sonoridad de las ciudades. Lo primero que es importante señalar es que este tópico ha tomado dos vertientes que, a su vez, se complementan. La primera de ellas es la caracterización de la ciudad a partir de los sonidos que se producen en ella, pues en cada lugar existen ciertos sonidos que le permiten a sus habitantes reconocerlo (Polti, 2018); de igual manera, mediante la escucha cotidiana las personas hacen propios los lugares y se identifican con ellos (Atienza, 2008).

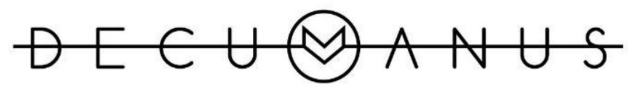

REVISTA INTERDISCIPLINARIA SOBRE ESTUDIOS URBANOS 
Por lo tanto, la primera concepción de identidad sonora se puede entender como todas aquellas sonoridades propias de un sitio en específico, que permiten diferenciarlo de otros lugares (Carles y Palmese, 2004). En este contexto, la identidad sonora comprendida como sonidos emblemáticos del lugar, se inscribe dentro de la geografia simbólica del paisaje cultural (Domínguez, 2015). Si bien la identidad sonora es parte de la memoria y los imaginarios de las personas que habitan un lugar determinado, esta identidad está en constante transformación, ya que es un reflejo de los cambios físicos y socioculturales que se suscitan en un espacio delimitado (Cerdà, 2012). En este punto es importante reiterar lo que ya se ha expuesto sobre los cambios vertiginosos que se dan en la ciudad contemporánea, así como la tendencia a uniformizar las ciudades, lo cual afecta a la identidad sonora de los lugares.

También es oportuno señalar que la identidad sonora no son solamente los sonidos que más predominan en un sitio o los sonidos endémicos del lugar, sino también todos aquellos que mediante el acto de escuchar adquieren mayores cargas significativas produciendo sentimientos de arraigo y pertenencia en los habitantes. Esto da pie para el otro constructo de la identidad sonora en donde el sonido no solo es parte inherente del territorio, sino también de una subjetividad, debido a que la escucha como medio epistémico también apela a una individualidad en la cual el sonido adquiere valores y significados, a partir de las experiencias propias de cada persona. En esta variante la identidad sonora se explica como todos aquellos sonidos que generan determinados tipos de emociones o recuerdos en una persona, a partir de las significaciones individuales que estimula el sonido en el sujeto.

Ambas concepciones de la identidad sonora, tanto la que se puede denominar como territorial/colectiva como la individual, conllevan a una cohesión del sujeto con la comunidad y el espacio. Dicho de otra manera: el sonido y -más que el sonido- la escucha contribuyen a la creación de espacios compartidos (LaBelle, 2010). Por lo que se puede argumentar que el espacio público es un sitio común que se compone no solo de elementos físicos, sino también simbólicos como la identidad, así como de otras prácticas y significaciones que derivan del acto de escuchar. Ambos constructos (espacio público y la escucha) se reproducen recíprocamente de manera constante y se resignifican a través del tiempo y las transformaciones objetivas y subjetivas, que tanto sus habitantes como el espacio físico sufren en su evolución natural o mediante las dinámicas globales impuestas.

\section{Conclusión}

La escucha es un elemento epistémico que permite una experimentación, interpretación y significación de la ciudad. En el contexto de las urbes contemporáneas y sus cambios constantes, la escucha conlleva a formas particulares de estar reaprendiendo la ciudad al mismo ritmo que esta se transforma, es decir, una acusia de la urbe en constante evolución. A su vez, la escucha dictamina una gran cantidad de dinámicas socioculturales de la ciudad, tales como la comunicación, la identidad, el arraigo y la territorialidad. Por otro lado, la escucha es un elemento que permite diversas formas de vivir y reproducir el espacio público, tanto de forma individual como colectiva.

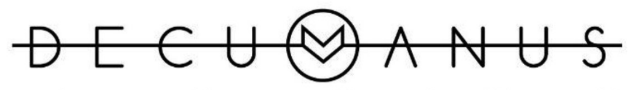

REVISTA INTERDISCIPLINARIA SOBRE ESTUDIOS URBANOS 
Por último, es importante insistir que tanto el sonido como la escucha, son variables necesarias a considerar en la planeación, construcción, remodelación y planes de reordenamiento territorial de las urbes. Ante esto, es importante recalcar la necesidad de tomar en cuenta el sentir ciudadano respecto a las repercusiones sensoriales que pueden traer las transformaciones en la ciudad, por lo que es necesario promover el trabajo etnográfico que, aunque aquí se ha apelado a la necesidad de una etnografía de la escucha en la urbe, es importante llevar esto a un campo holístico y realizar trabajos etnográficos que contemplen todos los canales sensoriales con la intención de traer mejoras en las formas de experimentar, habitar y vivir las ciudades.

\section{Referencias}

Argüello, P. (2018). Epicentros de revitalización en el Centro Histórico de la Ciudad de México. Gentrificación, apropiaciones y conflictos en torno al trabajo de músicos callejeros. Rev. Latinoam. Antrop. Trab., 3, 1-28.

Atienza, R. (2008). Identidad sonora urbana: tiempo, sonido y proyecto urbano. Les 4èmes Journées Européennes de la Recherche Architecturale et Urbaine EURAU'08: Paysage Culturel, 16(19). https:// halshs.archives-ouvertes.fr/halshs-00379907

Augoyard, J. (1997). La sonorización antropológica del lugar. En: M. Merlinck (Ed.), Hacia una antropología arquitectónica (pp. 205-219). Universidad de Guadalajara.

Barbanti, R. (2017). Elementos para una "acusia" de la ciudad. Panambí. Rev. Inv. Art., 4, 95-110.

Berenguer, J. (2017). Tránsito al límite de la ciudad. Por los campos acotados de ruido entre el sujeto y la colectividad. Panambí. Rev. Inv. Art., 4, 127-136.

Bieletto, N. (2019). Regímenes aurales a través de la escucha musical: Ideologías e instituciones en el siglo xxı. En: A. Domínguez (Ed.), Dossier "Modos de escucha". El oído pensante, $7(2), 111-134$.

Bull, M. (2004). Thinking about Sound, Proximity, and Distance in Western Experience: The Case of Odysseus's Walkman. En: V. Erlmann (Ed.), Hearing Cultures: Essays on Sound, Listening and Modernity (pp. 173-190). Routledge.

Carles, J., \& Palmese, C. (2004). Identidad sonora urbana. https://www.eumus.edu.uy/ eme/ps/txt/carles.html

Celedón, G. (2015). Problemas de frontera: sonidos -no- presentes. Reflexiones en torno al paisaje sonoro. Rev. Aural, 2, 10-14.

Cerdà, J. (2012). Observatorio de la transformación urbana del sonido: La ciudad como texto, derivas, mapas y cartografía sonora. Rev. Arte Polít. Ident., 7, 143-161.

De Gortari, J. (2013). Guía sonora para una ciudad. UAM/Ed. Juan Pablos.

Deávila, O. (2015). Los desterrados del paraíso: turismo, desarrollo y patrimonialización en Cartagena a mediados del siglo xx. En: A. Abello, \& F. Flórez (Eds.), Los desterrados del paraíso. Raza, pobreza y cultura en Cartagena de Indias (pp. 123-146). Maremágnum.

Delgadillo, V. (2015). Patrimonio urbano, turismo y gentrificación. En: V. Delgadillo et al. (Eds.). Perspectivas de la gentrificación en México y América Latina (pp. 113-132). UnAM.

Domínguez, A. (2011). Digresión sobre el espacio sonoro. En torno a la naturaleza intrusiva del ruido. Cuad. Viv. Urb., 4(7), 26-36.

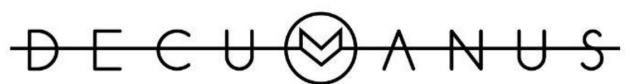

REVISTA INTERDISCIPLINARIA SOBRE ESTUDIOS URBANOS
Núm. 7. Vol. 7. Mayo 2021-Octubre 2021. Instituto de Arquitectura, Diseño y Arte. Universidad Autónoma de Ciudad Juárez. ISSN: 2448-900X 
----- (2014). Vivir con ruido en la Ciudad de México. El proceso de adaptación a los entornos acústicamente hostiles. Est. Dem. Urb., 29(1), 89-112.

----- (2015). El poder vinculante del sonido. La construcción de la identidad y la diferencia en el espacio sonoro. Alter. Línea, 25(50), 95-104. https://alteridades.izt.uam.mx/

----- (2017). A un grito de distancia. Comunidades acústicas y culturas aurales en torno al uso de la voz alta. En: A. Domínguez, \& A. Zirión (Eds.), La dimensión sensorial de la cultura. Diez contribuciones al estudio de los sentidos en México (pp. 35-55). Ediciones del Lirio-UAM-I.

----- (2019). El oído: un sentido, múltiples escuchas. Presentación del dossier Modos de escucha. En: A. Domínguez (Ed.), Dossier "Modos de escucha". El oído pensante, 7(2), 92-110.

Erlmann, V. (2010). Reason and Resonance: A History of Modern Aurality. Zone Books.

Feld, S. (2015). Acoustemology. En: D. Novak, \& M. Sakakeeny (Eds.), Keywords in Sound (pp. 12-21). Duke U. Press.

García, J. (2019). Conocimientos en resonancia: hacia una epistemología de la escucha. En A. Domínguez (Ed.), Dossier “Modos de escucha”. El oído pensante, 7(2), 135-154.

García, N. (2005). Alarmas y sirenas: sonotopías de la conmoción cotidiana. En: Espacios sonoros, tecnopolítica y vida cotidiana (pp. 12-25). Orquestra del Caos e Institut Català d'Antropologia.

Gasca, C. (2016). Habitar el patrimonio: experiencias espaciales de los habitantes del Centro Histórico Potosino. Rev. Cienc. Soc. Hum., 37(80), 11-38.

Hiernaux, D., \& González, C. (2014). Gentrificación, simbólica y poder en los centros históricos: Querétaro, México. Rev. Elect. Geog. Cienc. Soc. Univ. Barc., 12(493). http://www. ub.edu/geocrit/sn/sn-493/493-12.pdf

Krause, B. (1993). The Niche Hypothesis: A Virtual Symphony of Animal Sounds: The Origins of Musical Expression and the Health of Habitats. Soundsc. News., 6. World Forum for Acoustic Ecology.

LaBelle, B. (2010). Acoustic Territories: Sound Culture and Everyday Life. The Continuum International Publishing Group.

Lipovetsky, G. (2014). La sociedad del hiperconsumo. Alicante: Biblioteca Virtual Miguel de Cervantes. http://www.cervantesvirtual.com/nd/ark:/59851/bmc7s9j3

López, I. (2001). El significado del medio ambiente sonoro en el entorno urbano. Est. Geog., 62(244), 447-466.

Paparrigopoulos, K. (2017). Músicas, sonidos, ruidos de la ciudad: hacia una polifonía sonora. Panambí. Rev. Inv. Art., 4, 65-78.

Pardo, C. (2017). Capitalismo, sonidos y procesos de subjetivación en la ciudad contemporánea. Panambí. Rev. Inv. Art., 4, 111-124.

Pelinski, R. (2007, junio). El oído alerta: modos de escuchar el entorno sonoro. Actas del I Encuentro Iberoamericano sobre Paisajes Sonoros. Madrid, España. https://cvc.cervantes.es/artes/paisajes_sonoros/p_sonoros01/pelinski/pelinski_01.htm

Polti, V. (2011, noviembre-diciembre). Aproximaciones teórico-metodológicas al estudio del espacio sonoro. La antropología interpelada: nuevas configuraciones político-culturales en América LLatina. Actas X Congreso Nacional de Antropología. Buenos Aires, Argentina, pp. 2-13.

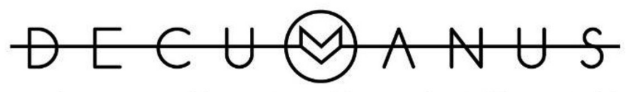

REVISTA INTERDISCIPLINARIA SOBRE ESTUDIOS URBANOS
Núm. 7. Vol. 7. Mayo 2021-Octubre 2021. Instituto de Arquitectura, Diseño y Arte. Universidad Autónoma de Ciudad Juárez. ISSN: 2448-900X 
----- (2018, septiembre). Subjetividad, identidad y memoria a través del sonido. Mundos sonoros: cruces, circulaciones, experiencias. Actas del I Simposio Internacional de Arte Sonoro, UNTREF. Buenos Aires, Argentina, pp. 1-7. https://artesonoro.untref.edu.ar/edicion-2018

Rice, T. (2003). Soundselves: An Acoustemology of Sound and Self in the Edinburgh Royal Infirmary. Anthropol. Today, 19(4), 4-9.

Roldán, O. (2017). Gentrificación en centros históricos: una discusión conceptual. Devenir, Rev. Est. Patr. Edif., 4(7), 69-82.

Sack, R. (1983). Human Territoriality: A Theory. Annals Assoc. Amer. Geograp., 73(1), 55-74. http://www.jstor.org/stable/2569346

Schafer, M. (1977). The Tuning of the World. Destiny Books.

Secretaría de Cultura (2013). La identidad sonora de México, presente en el London MexFest: Pablo Delgado. Recuperado el 10 de octubre de 2020, de https://www.gob.mx/cultura/ prensa/la-identidad-sonora-de-mexico-presente-en-el-london-mexfest-pablo-delgado Simmel, G. (2016). Las grandes ciudades y la vida intelectual. Hermida.

Thibaud, J. (2003). The Sonic Composition of the City. En: B. Michael, \& L. Back (Eds.), The Auditory Culture Reader (pp. 329-341). Berg Publishers.

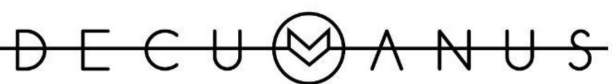

REVISTA INTERDISCIPLINARIA SOBRE ESTUDIOS URBANOS 